\title{
HACIA UN ESTUDIO DEL EMPHASIS EN LA OBRA POÉTICA DE ANTONIO GAMONEDA
}

Idoia ARBILLAGA

I. E. S. Poeta Julián Andúgar (Murcia)

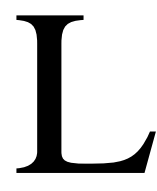

a figura retórica del emphasis se define como el empleo de una palabra de exiguo contenido significativo para la designación de un contenido significativo mayor, más preciso y de menor extensión significativa. Es considerado una especie de sinécdoque, pues se presenta como una inexactitud elocutiva encubridora que, a través del contexto o la pronuntiatio, define una voluntas de designación más exacta que persigue el efecto de asombro o desconcierto. De este modo la figura permite dar a entender más de lo que se expresa.

Quintiliano advierte que:

Puede parecer que las palabras, que dan a entender más de lo que ellas dice, se deben poner en la categoría de la perspicuitas, pues favorecen la comprensión; yo, sin embargo, aplicaría más gustosamente esta forma de énfasis en relación con el adorno del discurso, porque esta figura no tiene por objeto que se entienda algo, sino que se entienda más. ${ }^{1}$

Quintiliano asegura que, a causa de la proximidad que esta figura presenta respecto a la excelencia del adorno, el énfasis ofrece «un sentido más profundo que el que las palabras por sí mismas dan a conocer» $\mathrm{y}$ «se presenta de dos formas: la primera, que da a entender más de lo que dice; la segunda, que da a entender lo que no dice ${ }^{2}$. Ambas especies de emphasis se observan claramente en la poesía de Antonio Gamoneda, según se observará3 ${ }^{3}$

\footnotetext{
${ }^{1}$ «Possunt videri verba, quae plus significant quam eloquuntur, in parte ponenda perspicuitatis: intellectum enim adiuvant; ego tamen libentius emphasin retulerin ad ornatum orationis, quia non ut intellegatur efficit, sed ut plus intellegatur». II 8.2.11. M.F. Quintiliano, 5 vols., 1996-2000. Para esta y las subsiguientes citas de la Retórica de Quintiliano seguimos esta edición. Para otros aspectos del ornatum en la retórica aparecidos en el texto véase esta misma y H. Lausberg, 1999, 3 vols.

2 «Vicina praedictae <scil. brachylogiae> sed amplior virtus est $\varepsilon \dot{\mu} \varphi \alpha \sigma \iota \varsigma$, altiorem praebens intellectum quam quem verba per se ipsa declarant; eius duae sunt species: altera quae plus significant quam dicit, altera quae etiam id quod non dicit». Tा 8.3.83.

${ }^{3}$ Todos los versos citados y los extractos de la obra del autor pertenecen a las siguientes ediciones: A. Gamoneda, Esta luz. Poesía Reunida (1947-2004) (2004); Sólo luz. Antología poética (1947-1998) (2000); Libro del frío (2000); Arden las pérdidas (2003); Edad (Poesía 1947-1986) (1988); Cecilia y otros poemas (2007). Y los breves textos de autoanálisis de su poética: Id., «Mi poesía ha estado siempre en la perspectiva de la muerte», Pliego de poesía (1995); «Poesía, existencia, muerte» Tropelías: Revista de Teoría de literatura y Literatura Comparada (2001-2003,549-556).
} 
En otro orden, pero igualmente pertinente aquí, Quintiliano refiere un uso más convencional del énfasis a través de su ya arquetípico ejemplo: «HHay que ser hombre!» ${ }^{4}$. El sustantivo «hombre» adquiere, así, un contenido significativo mayor y más preciso que el que usualmente contiene. Mediante un contenido significativo inexacto se expresa un contenido designativo más exacto.

El carácter de sugerencia del contexto resulta determinante para la expresión de la figura. Compárese la opuesta acepción semántica que el sustantivo hombre presenta en los siguientes ejemplos: «Hay que ser hombre!» con «Homero y Demóstenes son los mejores, pero son hombres»`.

Antonio Gamoneda, a través de la repetitio y sirviéndose de la intensificación expresiva que le proporciona el emphasis, constituye una red tópica sobre la cual sustenta su discurso poético; lo que se observa tanto en la dispositio de su lenguaje sentencioso como en la metaforología sobre la cual erige su lenguaje figurado.

El objeto de este breve análisis es determinar, siquiera esquemáticamente, la peculiar manera en que Gamoneda emplea el emphasis (muchas veces en consonancia con otras figuras retóricas) y la manera en que esta figura le sirve para reforzar el carácter expresivo y la singularidad de sus principales topoi.

Desde sus primeros poemarios, el autor conforma unos determinados campos semánticos y un particular léxico sobre los que asienta los principales tópicos de su discurso: la destrucción y la muerte, el dolor, la ira y la violencia, y el cuerpo.

En lo que se refiere a la contiguidad de uso que entre el emphasis y otras figuras realiza Gamoneda, conviene referir las figuras de la repetitio, la sinestesia y la aliteración. La repetitio se asocia específicamente a la creación y permanencia en su obra de unas isotopías que vertebran el discurso a través de un conjunto léxico-semántico del que daremos cuenta al referirnos tanto a los campos semánticos más determinantes como a los topoi del discurso poético del autor.

En cuanto a la sinestesia, una figura asociada al gusto gamonediano por la expresión de lo sensorial - preferencia ya señalada en su día por Miguel Casado ${ }^{6}$-, se observan numerosas metáforas enfáticamente expresadas y asociadas a distintos usos derivados de esta figura retórica. En todas estas imágenes el autor subraya la supremacía de lo sensorial, de los sentidos. Así, en relación con el gusto, son abundantes las metáforas como: lame las sombras de tu madre, un perro come en mi corazón, lame los parietales torturados, el humo de la serenidad hierve en mi boca.

Respecto al sentido del olfato, aparecen metáforas como: hueles su orina silenciosa. Respecto al tacto: Las manos en el fuego, frío de azufre. Asociadas al oído, son claras metáforas y sinestesias (o usos derivados de esta figura) como: Pobreza que hace crujir la luz (donde confronta una sensación visual con una auditiva), o la paciencia excavando tumbas en el sonido, o más indirectas, como el grito de la viuda loca, manos clavadas en los tímpanos, silban en tímpanos sangrientos.

\footnotetext{
${ }^{4}$ «Est in vulgaribus quoque verbis emphasis: 'virum esse oportet', et 'homo est ille', et 'vivendum est; adeo similis est arti plerumque natura'». II 8.3.86.

${ }^{5}$ Ibid., loc.cit.

${ }^{6}$ M. Casado, «Introducción», en A. Gamoneda, Edad (Poesía 1947-1986), op. cit, 9-61. Véase también Id., «Epílogo de Miguel Casado», en A. Gamoneda, Esta luz. Poesía Reunida (1947-2004), op. cit., 575-627.
} 
Más abundantes son las metáforas que el autor, con efectivos énfasis, asocia al sentido de la vista: las córneas abrasadas, en tus ojos la blancura, en tus ojos: llueve a través de la luz, la alegría y la piedad ardían en tus ojos, la luz hierve debajo de mis párpados, pesan las piedras en mis ojos, las uñas (...) arrancan nuestros ojos, bajo la actividad de las hormigas había párpados, se rompían vidrios dentro de mis ojos, etc. El emphasis permite en estas metáforas otorgar a los ojos un valor más allá de lo orgánico, lo físico. Gamoneda refiere unas veces la calidez afectiva que pueden transmitir unos ojos; otras transmite enfáticamente la impotencia de la mirada, el dolor por lo que ve, la imposibilidad de relatar lo que le descubre su mirada.

Por otra parte, advertía Quintiliano que a través de la pronuntiatio, el emphasis descubre una voluntas de designación más exacta que persigue el efecto de asombro o desconcierto. El correlato más exacto que la ponuntiatio encuentra en la elaboración del discurso poético es la prosodia y todos sus mecanismos rítmicos y fonéticos. El emphasis halla, pues, en la lírica una forma de expresión muy efectiva a través de figuras como la aliteración.

También de esta asociación entre ambas figuras se sirve Gamoneda. Específicamente, en el Libro del frío se reitera la terminación sustantiva - dad, lo que crea aliteraciones de /d/ que recrean una prosodia acusadamente enfática: obscenidad, verdad, posibilidad, fertilidad, inmovilidad, oscuridad, suavidad, tempestad, extremidad, lubricidad... Jacques Ancet considera, en su breve Prólogo al Libro del frío ${ }^{7}$, que el autor busca solo repetir o recrear la palabra 'edad'. Si bien, consideramos que Gamoneda va más allá y ofrece ese subsiguiente uso retórico que el énfasis posee en la pronuntiatio, al crear esas enfáticas y expresivas aliteraciones. Huelga recordar que en su avance poético, Gamoneda despoja su poesía de todo cuanto no resulte esencial y revelador, le resta adjetivos y también por ello otorga aquí preeminencia a estos sustantivos.

A continuación procede realizar un sucinto análisis acerca de la forma en que el emphasis permite al autor conformar, junto con la repetitio, sus principales campos semánticos, el léxico de sus topoi. Así, adelantábamos que distintos campos semánticos prevalecen en la constitución de esos tópicos: la destrucción y la muerte, el dolor, la ira y la violencia, y el cuerpo.

Las metáforas asociadas al cuerpo resultan muy numerosas en toda la obra de Gamoneda, cuerpo y escatología, cuerpo y enfermedad sustentan infinidad de metáforas en todos sus poemarios. Es este uno de los grupos metafóricos, el del tópico del cuerpo y su degradación ${ }^{8}$, en donde el emphasis halla sus cotas más expresivas: Hierven las cámaras corporales (las tumbas, la descomposición de los cuerpos, los cadáveres de la guerra se entrevén en algunas de las metáforas más enfáticas del autor), una cuchillada entre los dientes, la luz de mis dientes, mierda y amor bajo la luz terrestre, goteándonos muerte en los dientes y en los ojos, como la cólera en el hígado, ¿en qué cal viva pondrá los ojos?, rojo corazón desmenuzado, un pétalo herido en tu rostro, el rostro aplastado, el espanto oprímele los

\footnotetext{
${ }^{7}$ J. Ancet, «El éxtasis blanco», en A. Gamoneda, Libro del frío, op. cit., 7-21.

${ }^{8}$ Aparecen insistentemente sustantivos y adjetivos como: Fístula, dentadura, muslos, enfermedad, médulas, vientre, saliva, pezones, cuerpo, labios, placenta, deposición, orina -y derivados-, sangre -sangriento, ensangrentados, etc.-, excrementos, vejez-viejo, vieja, etc.-, hedor, hiel, coágulos, etc.
} 
ojos, vi huesos torturados, cabezas laceradas, hormigas debajo de las llagas, etc. ${ }^{9}$ Los estados del dolor y la melancolía asociados al cuerpo también son expresados con gran emphasis: la melancolía cableada del corazón al intestino, el olor a tristeza de mis manos, orientas a tus venas la agonía, sangre de desecho, tira el corazón al fuego, esta pena arterial, etc.

En Cecilia y otros poemas y en Exentos III y IV: el énfasis no viene dado por la escatología y la crudeza de las metáforas, en contraste aquí asocia la luz al cuerpo: luz dentro de mis venas, tu piel tenía la suavidad de los sueños, la eternidad rozó un instante mis labios, en tus ojos: llueve a través de la luz, retienes en tus ojos la blancura, llena de luz: tus cabellos en mis manos, mis venas se vaciaban en la luz, se abrió en mí una esfera de luz. No obstante, la asociación de imágenes positivas no es representativa de la metaforología general asociada al cuerpo a lo largo de toda su trayectoria poética.

Francisco Gómez-Porro encuentra que ya en Cecilia y otros poemas hay una reconciliación con la vida y con el cuerpo por parte del autor, lo cual subscribo ${ }^{10}$; si bien, considero que esta reconciliación se aprecia más acusadamente en Arden las pérdidas poemario al que pertenecen imágenes como: Inmóvil en sus arterias y en sus huesos, un tiempo en que mi cuerpo participaba de la luz, el sueño era otra vida dentro de mi cuerpo. Se aprecia claramente en esta obra un pacto con la vida, una asunción de las pérdidas ya desde la serenidad o -como afirmó el autor-desde «la oquedad quemante de esas pérdidas».

En cuanto a la destrucción y la muerte, el propio autor ha realizado declaraciones como las contenidas en sus textos «Mi poesía ha estado siempre en la perspectiva de la muerte» o en «Poesía, existencia, muerte», y también en algún Preámbulo, donde él mismo describe lo que denomina su «poética de la muerte», influenciada por la tristeza de su madre viuda, la guerra, su pérdida de fe en Dios, etc.

La muerte ${ }^{11}$ es indudablemente el topos principal en Gamoneda. Muerte y destrucción dan lugar a toda una serie de metáforas cuyo mayor capacidad de asombro lo proporciona una vez más la figura del emphasis. Sin duda sobrecogen metáforas como: Los muertos vibran, un muerto te cruza la sangre, el sabor a muerto de su lengua, viene la muerte por correspondencia, un hijo desgajado, lodos sin tumba, el hervor germinal del enterrado, roba la muerte mis huesos, se lavan muertos, la ejecución de las alondras, lentos cuchillos entran en los sepulcros, todo está ensangrentado. Al igual que hombre representaba acepciones distintas según el contexto que el emphasis le otorgara, el sustantivo

\footnotetext{
${ }^{9}$ El ácido que depositas sobre mi salud, uñas abrasadas, letrinas fértiles, 'suavemente, orina', los hilos negros de su corazón, viene a tus manos como una lengua luminosa y se desliza en las grasientas células, cartílagos abrasados, sombra rectal, negras entrañas musicales, su aguja fría en mi corazón, el hueso de la misericordia, la pureza de rostros, uñas de acero, lágrimas en úlceras amarillas, la vagina maternal que llora, sobre mi carne paso, mi vejez tuerce sus huesos y quema sus cabellos, los huesos de su rostro como frutos de sombra, luz en los cartílagos y las venas, hay úlceras en la pureza, esta pena arterial, la médula negra de la policía, en mi corazón hay hormigas, excrementos cubiertos de rocío, la edad del hierro en la garganta, de tu boca caen sílabas negras.

${ }^{10}$ F. Gómez-Porro, «El cantor de las heridas. Notas para el estudio del cuerpo vulnerado en la obra de Antonio Gamoneda», en A. Gamoneda, Cecilia y otros poemas, op. cit., 103-111.

11 El léxico es igualmente abundante a este respecto: Vejez -viejo, vieja, etc.-, mortaja, fúnebre, suicidio -y sus derivados-, tinieblas, agujero, osario, sepultada, matar-muere, muerte, muerto, etc.-, agonía, espectro, sombra, siniestra, negras, destrucción, negación, oscura, abismo, óxido-y derivados-, ruinas, secano, etc.
} 
sangre y sus derivados adquiere acepciones distintas: sangre en tanto que herencia genética (o vínculo afectivo) o sangre en su acepción más negativa de herida que no cicatriza, dolor, angustia, ira, etc.

Los grupos metafóricos acerca de la muerte se ven muchas veces reforzados por el carácter enfático de imágenes asociadas al dolor y al desconsuelo ${ }^{12}$ : La oscuridad del llanto, la sangre más desamparada, espada de amargura, mirar la vida desde lo oscuro, un pájaro triste canta entre las ramas negras, un dios caído en el dolor, la pureza de la ira, potencia degolladora de dolor, siglos de sombra se elevaron, si el dolor se apretase en la herida, duras manos torturando, el miedo habla, las hormigas se dirigen hacia tus llagas, la nuez vómica como algodones exprimidos dentro de una llaga, ubres atormentadas, locas hormigas sobre algodones ensangrentados, el vendedor de sombra, alas desesperadas, tu cama sangrienta, la pureza azul de los cuchillos, sangre en las iglesias amarillas, etc.

Conforme evoluciona su obra y particularmente tras el Libro del frío, el autor deconstruye o desarticula más la imagen, le resta densidad adjetival y la hace avanzar hacia una esencialidad sustantiva. En Arden las pérdidas se encuentra en gran medida una abierta y clara clave de lectura respecto de la metaforología desarrollada en todo el corpus poético gamonediano. Aquí escribe en tiempo pretérito muchos de sus versos y se aprecia cierta intención clarificadora. Se instituyen ya un léxico y unos topoi que en ocasiones habían sido tensados semánticamente en una y otra dirección. Aquí parecen ya reposar en su significado definitivo. Escribe aquí el poeta:

\section{Al fin surgen las fuentes sangre, vértigo, luz, acero, lágrimas.}

Puro emphasis, repetitio y enumeratio de su léxico de siempre. La repetitio es una figura consustancial a la poesía, pero asociada al emphasis permite a Gamoneda reforzar unos tópicos que se sustentan sobre un léxico esencial que, junto con sus derivados, se repite a lo largo de todos sus poemarios: sangre, muerte, lágrimas, sombra, ojos, huesos, corazón, hormigas y otros sustantivos.

Para finalizar, conviene mencionar un último y más sutil uso que del emphasis realiza el poeta, se trata de una forma de emphasis semántico de pensamiento que define Quintiliano a través de una detractio de los verba y una adiectio de las res. Estas dos categorías modificativas de la dispositio permiten que el autor emplee un signo lingüístico y conceptual que superficialmente no aparenta una particular trascendencia, pero es -para el oyente atento- la expresión inefable de una realidad más amplia, oculta pero sugerida.

Quintiliano otorga un perfil más explícito a su definición cuando advierte que el autor del discurso emplea este emphasis «cuando quiere expresar algo determinado, pero no puede o no quiere

\footnotetext{
${ }^{12}$ Dolor, ira y violencia encuentran su expresión a través de un léxico muy específico: Atormentado, dolor -dolorosa, etc.-, pena, llorar-lágrimas, llanto, etc.-, amargura-amargo, amarga, etc.-, alaridos, sufrimiento, tristeza, angustiosa, abatidos, impotencia, espanto, miedo, soledad, humillaciones, miserias, vacío. Gritos, ira, coraje, feroz, tormento, mordida, degolladora, torturas, terrible, rayo, abrasadores, atacar, golpea, cuchillo, cuchilladas, llagar, maldita, heridos, coléricas, furiosas, espinas, desgarradas, escarnecido...
} 
en vista de las circunstancias [...]. Hay circunstancias que reclaman el emphasis de pensamiento: juego, respeto, temor» ${ }^{13}$.

Sin duda no se puede hablar de Gamoneda sin referir aquella oscura realidad social, política e histórica que tantas veces nutrió sus versos. El poeta no se sirve de este emphasis para realizar un directo ejercicio de crítica política y social, sino para acercarnos y permitirnos sentir la oscuridad del momento histórico y vital del que él mismo fue testigo. El pavor de lo histórico es aprehendido junto a lo oscuro de la íntima biografía vital del poeta. Basten, para ilustrar esta categoría de la figura retórica, imágenes o sentencias ya citados aquí, como aquellas que continuamente refieren la sangre, iglesias amarillas, espadas, cuchillos, parietales torturados, el miedo que habla, manos torturando, un dios caído, la médula negra de la policía, y tantas otras que aluden al miedo, el dolor por la guerra, las muertes, la represión, la falta de libertades, etc. Cumple así el autor con la fundamental, y ya referida, premisa quintiliana establecida para el emphasis: otorgar al texto «un sentido más profundo que el que las palabras por sí mismas dan a conocer».

En conclusión, se observa, pues, que el emphasis se presenta en el discurso gamonediano como una figura semántica o de pensamiento, en ocasiones asociada a los usos derivados de la sinestesia, a la aliteración o a la repetición; pero siempre como una figura determinante tanto en la conformación de sus principales topoi como en el carácter de intensificación expresiva que el autor sabe otorgarle a su lenguaje sentencioso, por un lado, y a su lenguaje figurado, por otro. Imagen y sentencia se ven igualmente completadas por los muy acertados y distintos usos que del emphasis realiza Gamoneda, poeta del sobrecogimiento que construye esa particular e intensa «poética de la muerte», que tantas veces rebasa y casi conmociona al lector atento.

\section{Referencias bibliográficas}

ANCET, Jacques, «El éxtasis blanco», A. Gamoneda, Libro del frío, Valencia, Germanía, 2000, 7-21. CASADO, Miguel, «Introducción», Edad (Poesía 1947-1986), ed. Miguel Casado, Madrid, Cátedra, 1988, 9-61.

—, «Epílogo», Esta luz. Poesía Reunida (1947-2004), Barcelona, Círculo de Lectores-Galaxia Gutemberg, 2004, 575-627.

Gamoneda, Antonio, Edad (Poesía 1947-1986), ed. Miguel Casado, Madrid, Cátedra, 1988.

—_, «Mi poesía ha estado siempre en la perspectiva de la muerte», Pliego de poesía, 1995.

— Sólo luz. Antología poética (1947-1998), Valladolid, Junta de Castilla y León, 2000.

—_, Libro del frío, Valencia, Germanía, 2000.

— - «Poesía, existencia, muerte», Tropelías: Revista de Teoría de literatura y Literatura Comparada, núms. 12-14 (2001-2003), 549-556.

_-, Arden las pérdidas, Barcelona, Tusquets, 2003.

— Esta luz. Poesía Reunida (1947-2004), Barcelona, Círculo de Lectores-Galaxia Gutemberg, 2004.

\footnotetext{
${ }^{13}$ Quintiliano, Institutio Oratoria, op.cit., 906.
} 
38 Tropelías. Revista de Teoría de la Literatura y Literatura Comparada, 21 (2014)

Idoia Arbillaga

Cecilia y otros poemas, Madrid, FCE, 2007.

GómEZ-PORRO, Francisco, «El cantor de las heridas. Notas para el estudio del cuerpo vulnerado en la obra de Antonio Gamoneda», A. Gamoneda, Cecilia y otros poemas, Madrid, FCE, 2007, 103111.

LAUSBERG, Heinrich, Manual de Retórica literaria, Madrid, Gredos, 1999, 3 vols.

Quintiliano, Marco Fabio, Institutio Oratoria, ed. A. Ortega, Salamanca, Universidad Pontificia de Salamanca-Caja Duero,1996-2000, 5 vols. 